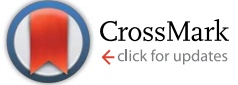

Cite this: RSC Adv., 2017, 7, 13250

Received 23rd November 2016 Accepted 20th February 2017

DOI: 10.1039/c6ra27216a

rsc.li/rsc-advances

\section{Hierarchical $\mathrm{CuBi}_{2} \mathrm{O}_{4}$ microspheres as lithium-ion battery anodes with superior high-temperature electrochemical performance $\uparrow$}

\author{
Hong Yin, $\$$ Ming-Lei Cao, $\$$ Xiang-Xiang Yu, $\$$ Chong Li, Yan Shen* \\ and Ming-Qiang Zhu*
}

In the present report, hierarchical $\mathrm{CuBi}_{2} \mathrm{O}_{4}$ microspheres are prepared through a hydrothermal route, and applied as anode materials for LIBs. The hierarchical $\mathrm{CuBi}_{2} \mathrm{O}_{4}$ microspheres of diameter $2.0-4.0 \mu \mathrm{m}$ are assembled by crystalline tetragonal nanoparticles with a size of 50-60 nm. The electrochemical performance of the hierarchical $\mathrm{CuBi}_{2} \mathrm{O}_{4}$ microspheres shows strong temperature-dependence whereby higher temperatures evidently enhance the electrochemical performance. At an elevated temperature of $70{ }^{\circ} \mathrm{C}$, a reversible capacity of $525.1 \mathrm{~mA} \mathrm{~h} \mathrm{~g}^{-1}$ has been achieved after 500 cycles at a current density of $100 \mathrm{~mA} \mathrm{~g}^{-1}$. Even after being cycled at a high current density of $6.4 \mathrm{~A} \mathrm{~g}^{-1}$, the hierarchical $\mathrm{CuBi}_{2} \mathrm{O}_{4}$ microspheres are still able to deliver a capacity of $585 \mathrm{~mA} \mathrm{~h} \mathrm{~g}^{-1}$ when the current density is set back to $100 \mathrm{~mA} \mathrm{~g}^{-1}$. The superior high-temperature electrochemical performance of the hierarchical $\mathrm{CuBi}_{2} \mathrm{O}_{4}$ microspheres is ascribed to their hierarchical structure and outstanding thermostability.

\section{Introduction}

With the growing demand for intelligent electronic devices and the rapid development of electric transportation and renewable energy systems, numerous efforts have been made to explore advanced electrochemistry energy storage technologies. ${ }^{\mathbf{1 - 4}}$ Owing to their high energy density, long cycle life and environmental benignity, lithium ion batteries (LIBs) have become one of the dominant power sources for the above-mentioned applications..$^{5-8}$ However, the practical applications of LIBs are mainly limited to ambient temperature due to the large capacity fade and serious safety issues at extreme temperature conditions, especially at elevated temperature. ${ }^{9-11}$ Generally speaking, the poor high-temperature electrochemical performance and serious safety issues are associated with the intrinsic properties of electrode materials. Currently, commercial graphite-based anode materials show rapid capacity fading and limited rate capability, as well as serious security problems (thermal decomposition of the solid electrolyte interphase (SEI) layer and the facile formation of dendritic lithium) at elevated temperature. ${ }^{12-15}$ In addition, the theoretical capacity $\left(375 \mathrm{~mA} \mathrm{~h} \mathrm{~g}^{-1}\right)$ of the graphite-based anode materials is relatively low, which is far

Wuhan National Laboratory for Optoelectronics, School of Optical and Electronic Information, Huazhong University of Science and Technology, Wuhan 430074, China. E-mail: mqzhu@hust.edu.cn; ciac_sheny@mail.hust.edu.cn; Fax: +86 27 87793419; Tel: +862787793419

$\dagger$ Electronic supplementary information (ESI) available. See DOI: 10.1039/c6ra27216a

\$ These authors contributed equally to this work. from the demand of the upcoming markets of electric transportation and renewable energy systems. As a consequence, it could be highly desirable to develop high capacity anode materials which possess outstanding high-temperature electrochemical performance and good security.

Transition-metal oxides, a kind of most studied anode materials for LIBs, can store lithium through the conversion reaction or the alloying-de-alloying reaction, leading to high specific capacities. ${ }^{\mathbf{1 6 - 2 0}}$ Though the investigations on transitionmetal oxide anode materials have attracted extensive attentions, there are few reports relate to the high-temperature electrochemical performances of those electrode materials. ${ }^{21-23}$ Among various transition-metal oxides, it is reported that bismuthbased oxides have thermal contraction effect (negative thermal expansion). This unique property can play a vital role in enhancing the high-temperature electrochemical performance and security of electrode materials in elevated environment. ${ }^{24}$ By now, no investigation on high-temperature electrochemical performance of bismuth-based transition-metal oxides is reported, though they exhibit favourable lithium storage ability at room temperature. As a member of bismuth-based transitionmetal oxides, the $\mathrm{CuBi}_{2} \mathrm{O}_{4}$ has been widely explored in photocatalysis, solar hydrogen and capacitor. Nevertheless, to the best of our knowledge, direct application of $\mathrm{CuBi}_{2} \mathrm{O}_{4}$ as an anode material for LIBs has not been reported yet. ${ }^{25-31}$ We pay attention to this binary bismuth-based transition-metal oxide due to its multiple oxidation states. In fact, $\mathrm{CuBi}_{2} \mathrm{O}_{4}$ could be considered as a solid solution composite, which consists of $\mathrm{CuO}$ and $\mathrm{Bi}_{2} \mathrm{O}_{3}$. In consideration of numerous studies have demonstrated the high lithium storage ability of both $\mathrm{CuO}$ and 
$\mathrm{Bi}_{2} \mathrm{O}_{3} \cdot{ }^{17,18,24,32}$ We propose that $\mathrm{CuBi}_{2} \mathrm{O}_{4}$ could also possess favourable lithium storage ability. Altogether, the $\mathrm{CuBi}_{2} \mathrm{O}_{4}$ may be an ideal anode material with superior high-temperature electrochemical performance and good security due to its thermal contraction effect and potential lithium storage ability.

Herein, we report on hierarchical $\mathrm{CuBi}_{2} \mathrm{O}_{4}$ microspheres as anodes for LIBs. The hierarchical $\mathrm{CuBi}_{2} \mathrm{O}_{4}$ microspheres are prepared through a facile and eco-friendly hydrothermal process, which have a diameter of 2.0-4.0 $\mu \mathrm{m}$ and consist of numerous pristine tetragonal nanoparticles with a size of 50-60 nm. The hierarchical $\mathrm{CuBi}_{2} \mathrm{O}_{4}$ microspheres exhibit superior high-temperature performance for lithium storage. At an elevated temperature of $70{ }^{\circ} \mathrm{C}$, the hierarchical $\mathrm{CuBi}_{2} \mathrm{O}_{4}$ microspheres can deliver a reversible capacity of $525.1 \mathrm{~mA} \mathrm{~h} \mathrm{~g}^{-1}$ over 500 cycles at a current density of $100 \mathrm{~mA} \mathrm{~g}^{-1}$. Impressively, a high rate capacity of $261 \mathrm{~mA} \mathrm{~h} \mathrm{~g}^{-1}$ can be achieved when the current density increases to $6400 \mathrm{~mA} \mathrm{~g}^{-1}$. The superior hightemperature electrochemical performances are attributed to the unique hierarchical structure and outstanding thermostability of the hierarchical $\mathrm{CuBi}_{2} \mathrm{O}_{4}$ microspheres.

\section{Experimental}

\section{Preparation of hierarchical $\mathrm{CuBi}_{2} \mathrm{O}_{4}$ microspheres}

A typical experiment is as following: $2 \mathrm{mmol}$ of $\mathrm{Cu}\left(\mathrm{NO}_{3}\right)_{2} \cdot 3 \mathrm{H}_{2} \mathrm{O}$, $4 \mathrm{mmol}$ of $\mathrm{Bi}\left(\mathrm{NO}_{3}\right)_{3} \cdot 5 \mathrm{H}_{2} \mathrm{O}$ were dissolved in $50 \mathrm{ml}$ of $0.5 \mathrm{~mol} \mathrm{~L}^{-1}$ $\mathrm{HNO}_{3}$. After rapid magnetic stirring for $1 \mathrm{~h}, 23 \mathrm{ml}$ of $2 \mathrm{~mol} \mathrm{~L}^{-1}$ $\mathrm{NaOH}$ solution aqueous and $2 \mathrm{ml}$ of EG was gradually added. The resultant solution was stirred for another $3 \mathrm{~h}$. Then, the solution was transferred into a $125 \mathrm{ml}$ Teflon-line stainless steel autoclave and heated at $140{ }^{\circ} \mathrm{C}$ for $12 \mathrm{~h}$ in an oven. The resultant solid product was collected, washed several times with deionized water and dried.

\section{Material characterization}

Morphological characterizations of the hierarchical $\mathrm{CuBi}_{2} \mathrm{O}_{4}$ microspheres were performed by scanning electron microscopy (SEM, NOVA 450, FEI) and by transmission electron microscopy (TEM, G2 FEI). The crystalline structures of the as-prepared hierarchical $\mathrm{CuBi}_{2} \mathrm{O}_{4}$ microspheres were characterized by X-ray diffraction (XRD, Shimadzu XRD-6000). The thermostability of hierarchical $\mathrm{CuBi}_{2} \mathrm{O}_{4}$ microspheres was performed with TG measurement (Diamond TGA/DTA 6300) with a heating rate of $10^{\circ} \mathrm{C} \mathrm{min}^{-1}$ in air. The valence states analysis of hierarchical $\mathrm{CuBi}_{2} \mathrm{O}_{4}$ microspheres were performed with X-ray electron spectrometer (XPS, AXIS-ULTRA DLD-600W).

\section{Fabrication of hierarchical $\mathrm{CuBi}_{2} \mathrm{O}_{4}$ microsphere electrodes}

The hierarchical $\mathrm{CuBi}_{2} \mathrm{O}_{4}$ microsphere anodes were prepared by mixing $70 \mathrm{wt} \% \mathrm{CuBi}_{2} \mathrm{O}_{4}$ microspheres, $20 \mathrm{wt} \%$ Super $\mathrm{P}$, and 10 $\mathrm{wt} \%$ vinylidene fluoride (PVDF) to form a slurry, which was then coated onto a copper foil and dried at $90{ }^{\circ} \mathrm{C}$ overnight under vacuum. The area of the electrode is about $1.53 \mathrm{~cm}^{2}$ while the loading of the whole material is about $2.5 \mathrm{mg} \mathrm{cm}^{-2}$.

\section{Fabrication of Li-ion batteries}

Li-ion batteries were fabricated using lithium as anode and $1 \mathrm{~mol} \mathrm{~L}^{-1} \mathrm{LiPF}_{6}$ in a mixture of ethylene carbonate/diethyl carbonate (EC/DEC, $1: 1$ by volume) as the electrolyte. All the cells were assembled in a glove box with water/oxygen content lower than $0.1 \mathrm{ppm}$ and tested at room temperature.

\section{Electrochemical measurements}

The galvanostatic charge-discharge test was conducted on a LAND cycler (Wuhan Kingnuo Electronic Co., China). Cyclic voltammetric and electrochemical impedance spectroscopy measurements were carried out with the coin cells using a $\mathrm{CHI}$ 760D electrochemical workstation (ChenHua Instruments Co., China).

\section{Results and discussion}

\section{Characterization of hierarchical $\mathrm{CuBi}_{2} \mathrm{O}_{4}$ microspheres}

Fig. 1a shows the XRD pattern of the as-prepared sample. The sharp characteristic peaks indicate the sample is well crystallized. All of the XRD peaks can be indexed to the tetragonal $\mathrm{CuBi}_{2} \mathrm{O}_{4}$ (JCPDS no. 72-0493) and no impurity peaks can be detected, implying all the $\mathrm{Bi}(\mathrm{III})$ and $\mathrm{Cu}(\mathrm{II})$ precursors have formed $\mathrm{CuBi}_{2} \mathrm{O}_{4}$ solid solution. The fitting XPS peak data (Fig. 1b) of Bi element can match well with the standard binding energy values of $\mathrm{Bi}(\mathrm{III})$, indicating the absence of $\mathrm{Bi}(\mathrm{II})$. According to the research result of $\mathrm{F}$. Parmigiani about $\mathrm{CuO}$ electron spectroscopy, the binding energy of $944.50 \mathrm{eV}$ (Fig. 1c) could be ascribed to the characteristic satellite peak of $\mathrm{Cu}(\mathrm{II})$, which manifests the cuprum exists as a high oxidation state in $\mathrm{CuBi}_{2} \mathrm{O}_{4} \cdot{ }^{33}$ Meanwhile, the ratio of $\mathrm{Cu} / \mathrm{Bi}$ is calculated by the XPS spectra (Table $\mathrm{S} 1 \dagger$ ). The XPS spectra of oxygen demonstrate that the valence bond is oxygen with metal $(531.00 \mathrm{eV})$ rather than oxygen with oxygen (Fig. 1d). ${ }^{34}$ The EDX mapping images of $\mathrm{Bi}, \mathrm{Cu}$ and $\mathrm{O}$ elements are shown in Fig. S1. $\dagger$ The content of cuprum is relatively less than bismuth and oxygen, determined
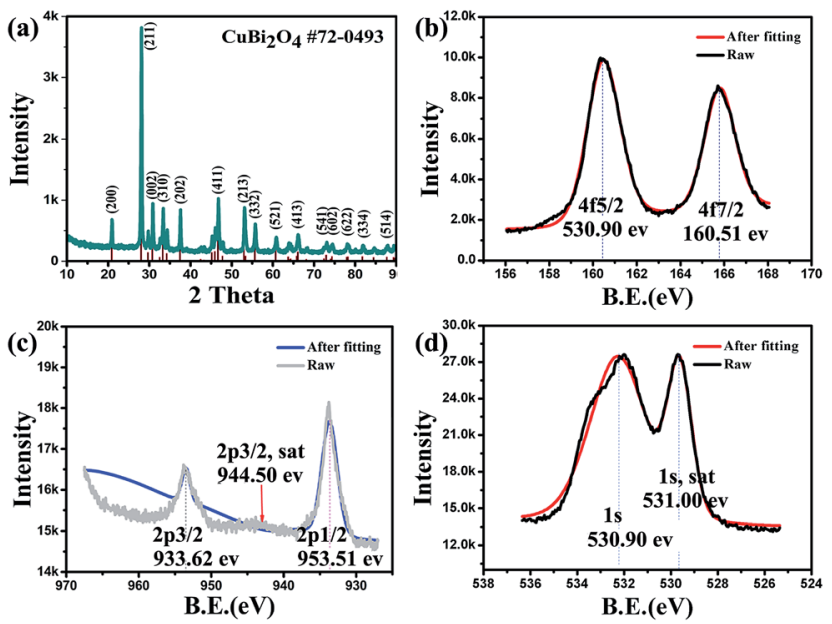

Fig. 1 (a) XRD pattern of the hierarchical $\mathrm{CuBi}_{2} \mathrm{O}_{4}$ microspheres. (b), (c) and (d) XPS spectra of $\mathrm{Bi}\left({ }^{\prime \prime I}\right), \mathrm{Cu}(I)$ and $\mathrm{O}(\mathrm{I})$, respectively. 
by the different shades. This result accords well with the composition of $\mathrm{CuBi}_{2} \mathrm{O}_{4}$.

The SEM image (Fig. 2a) reveals the as-prepared $\mathrm{CuBi}_{2} \mathrm{O}_{4}$ sample exhibits individual and uniform microspheres with hierarchical structure. The diameters of $\mathrm{CuBi}_{2} \mathrm{O}_{4}$ microspheres are in the range of 2.0 to $4.0 \mu \mathrm{m}$ (Fig. S2a $\dagger$ ). The highmagnification SEM image of the hierarchical $\mathrm{CuBi}_{2} \mathrm{O}_{4}$ microspheres is depicted in Fig. 2b, which indicates that the microspheres consist of a large number of primary tetragonal nanoparticles. The sizes of the primary tetragonal nanoparticles are measured to be 50-60 nm (Fig. S2b $\dagger$ ). The hierarchical $\mathrm{CuBi}_{2} \mathrm{O}_{4}$ microspheres assembled by primary nanoparticles could exhibit larger specific surface area than those bulk particles, supporting sufficient active sites for Liions insertion and extraction. The microstructure of the hierarchical microspheres was further investigated by TEM and HR-TEM. Fig. 2c is the TEM image of randomly selected microspheres, which displays the regular spherical morphology. HR-TEM investigation confirms the tetragonal texture of the $\mathrm{CuBi}_{2} \mathrm{O}_{4}$ nanoparticles (Fig. 2d), consistent well with the XRD study. The lattice fringes are clearly visible and the measured $d$-spacings of $0.24 \mathrm{~nm}$ and $0.31 \mathrm{~nm}$ correspond well to the (202) and (211) lattice planes, respectively. In addition, the hierarchical $\mathrm{CuBi}_{2} \mathrm{O}_{4}$ microspheres are able to keep their original morphology and structure at a high temperature of exceeding $500{ }^{\circ} \mathrm{C}$ (Fig. S3†), indicating their outstanding thermal stability. This unique property can largely determine the high-temperature electrochemical performance and security of the hierarchical $\mathrm{CuBi}_{2} \mathrm{O}_{4}$ microspheres for lithium storage.
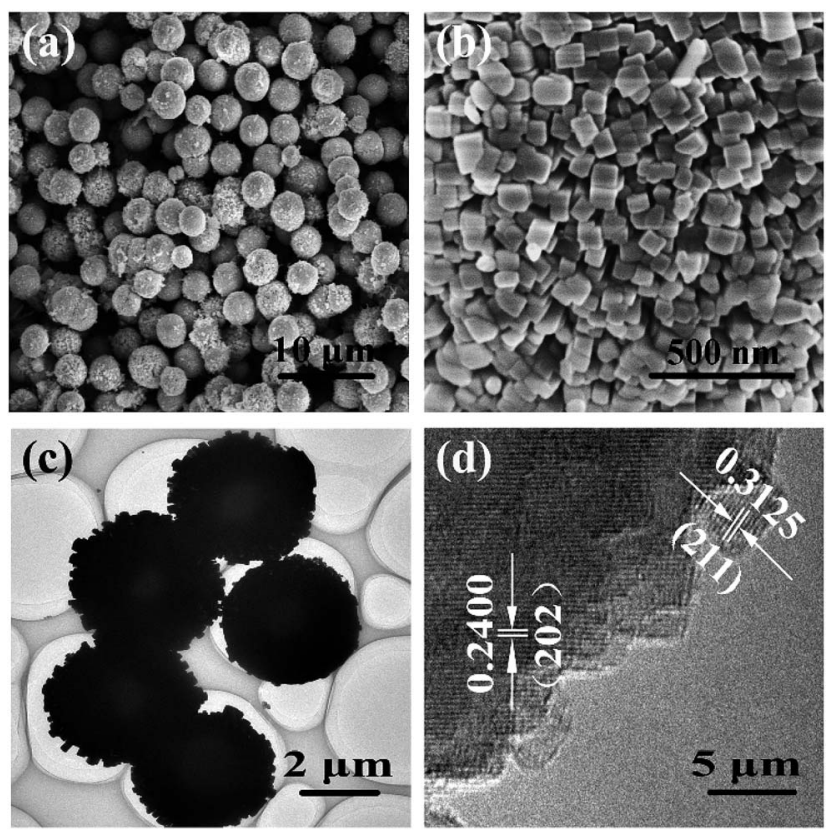

Fig. 2 (a) and (b) SEM images of the hierarchical $\mathrm{CuBi}_{2} \mathrm{O}_{4}$ microspheres at different magnifications. (c) TEM image of the hierarchical $\mathrm{CuBi}_{2} \mathrm{O}_{4}$ microspheres. (d) $\mathrm{HR}$-TEM image of the hierarchical $\mathrm{CuBi}_{2} \mathrm{O}_{4}$ microspheres.

\section{Electrochemical performance}

The electrochemical performance of the hierarchical $\mathrm{CuBi}_{2} \mathrm{O}_{4}$ microspheres was evaluated in standard CR2032 coin-type cells using lithium plates as counter electrodes. Fig. 3a shows the first two cyclic voltammograms (CV) curves of the hierarchical $\mathrm{CuBi}_{2} \mathrm{O}_{4}$ microspheres at a scan rate of $0.1 \mathrm{mV} \mathrm{s}^{-1}$ in the voltage range of 0.01-3.0 V. Four obvious cathodic peaks at potentials of $1.45 \mathrm{~V}, 1.18 \mathrm{~V}, 0.61 \mathrm{~V}$ and $0.40 \mathrm{~V}$ in the first CV curve can be ascribed to a multi-step lithiation process, involving (a) the peak at $1.45 \mathrm{~V}$ corresponds to the reduction of $\mathrm{Bi}(\mathrm{III})$ to $\mathrm{Bi}$, (b) the peak at around $1.18 \mathrm{~V}$ could be ascribed to $\mathrm{Cu}(\mathrm{II})$ reduction to $\mathrm{Cu}(\mathrm{I})$, (c) the less apparent peak at $0.61 \mathrm{~V}$ originates from $\mathrm{Cu}(\mathrm{I})$ reduction to copper and $(\mathrm{d})$ the peak at $0.40 \mathrm{~V}$ could be associated with both the formation of a solid electrolyte interface (SEI) layer and the alloying reaction of $\mathrm{Bi}$ with $\mathrm{Li}$ to form $\mathrm{Li}_{3} \mathrm{Bi}$. In the first anodic scan, the peak at around $1.01 \mathrm{~V}$ is attributed to de-alloying process and the peaks at 1.79 and $2.26 \mathrm{~V}$ are associated with the oxidation of $\mathrm{Bi}$ to $\mathrm{Bi}_{2} \mathrm{O}_{3} \cdot{ }^{24,35-37}$ Besides, the apparent anodic peak at $2.52 \mathrm{~V}$ could be ascribed to the oxidation of $\mathrm{Cu}$ to $\mathrm{CuO}$. In the second $\mathrm{CV}$ curve, the reduction peak of $\mathrm{Bi}(\mathrm{III})$ to $\mathrm{Bi}$ shifts to $1.62 \mathrm{~V}$. Interesting, the alloying peak is replaced by two obvious peaks at around $0.62 \mathrm{~V}$ and $0.37 \mathrm{~V}$, indicating the lithiation of Bi contains two steps (formation of $\mathrm{LiBi}$ and $\mathrm{Li}_{3} \mathrm{Bi}$ in turn). It is noted that the peak at $0.62 \mathrm{~V}$ overlaps with the reduction peak of $\mathrm{Cu}(\mathrm{I})$ to $\mathrm{Cu}$. The (a)

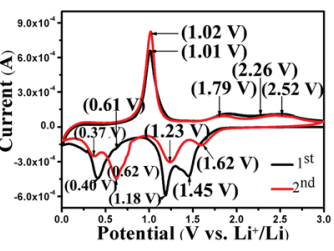

(c)

(d)

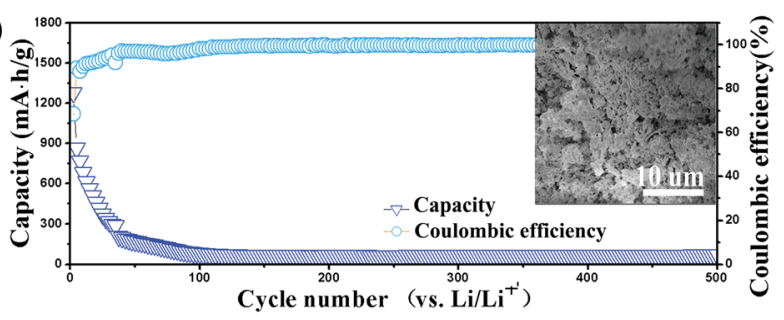

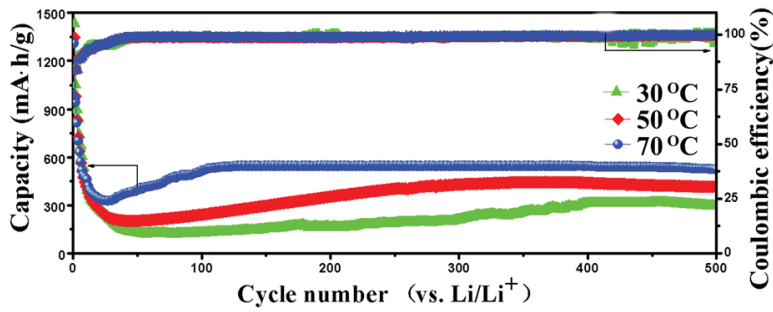

Fig. 3 (a) CV curves (first two cycles) of hierarchical $\mathrm{CuBi}_{2} \mathrm{O}_{4}$ microsphere from $0.01 \mathrm{~V}$ to $3 \mathrm{~V}$ at a scan rate of $0.1 \mathrm{mV} \mathrm{s}^{-1}$ at $30^{\circ} \mathrm{C}$. (b) First two charge-discharge voltage profiles at a current density of $100 \mathrm{~mA}$ $\mathrm{g}^{-1}$ at $70^{\circ} \mathrm{C}$. (c) Cycling performance of hierarchical $\mathrm{CuBi}_{2} \mathrm{O}_{4}$ microspheres at a current density of $100 \mathrm{~mA} \mathrm{~g}^{-1}$ at different temperatures. (d) Cycling performance of $\mathrm{CuBi}_{2} \mathrm{O}_{4}$ microparticles which are prepared by high temperature solid state method at $70^{\circ} \mathrm{C}$. 
overall electrochemical reaction process can be expressed as follow:

Discharging:

$$
\begin{gathered}
\mathrm{Bi}_{2} \mathrm{O}_{3}+6 \mathrm{Li}^{+}+6 \mathrm{e}^{-} \rightarrow 2 \mathrm{Bi}+3 \mathrm{Li}_{2} \mathrm{O}, E=1.62 \mathrm{~V} \\
\mathrm{Bi}+\mathrm{Li}^{+}+\mathrm{e}^{-} \rightarrow \mathrm{LiBi}, E=0.62 \mathrm{~V} \\
\mathrm{LiBi}+2 \mathrm{Li}^{+}+2 \mathrm{e}^{-} \rightarrow \mathrm{Li}_{3} \mathrm{Bi}, E=0.37 \mathrm{~V} \\
2 \mathrm{CuO}+2 \mathrm{Li}^{+}+2 \mathrm{e}^{-} \rightarrow \mathrm{Cu}_{2} \mathrm{O}+\mathrm{Li}_{2} \mathrm{O}, E=1.23 \mathrm{~V} \\
\mathrm{Cu}_{2} \mathrm{O}+2 \mathrm{Li}^{+}+2 \mathrm{e}^{-} \rightarrow 2 \mathrm{Cu}+\mathrm{Li}_{2} \mathrm{O}, E=0.62 \mathrm{~V}
\end{gathered}
$$

Charging:

$$
\begin{gathered}
\mathrm{Li}_{3} \mathrm{Bi} \rightarrow \mathrm{Bi}+3 \mathrm{Li}^{+}+3 \mathrm{e}^{-}, E=1.02 \mathrm{~V} \\
2 \mathrm{Bi}+3 \mathrm{Li}_{2} \mathrm{O} \rightarrow \mathrm{Bi}_{2} \mathrm{O}_{3}+6 \mathrm{Li}^{+}+6 \mathrm{e}^{-}, E=1.79 \mathrm{~V}, 2.26 \mathrm{~V} \\
\mathrm{Cu}+\mathrm{Li}_{2} \mathrm{O} \rightarrow \mathrm{CuO}+2 \mathrm{Li}^{+}+2 \mathrm{e}^{-}, E=2.52 \mathrm{~V}
\end{gathered}
$$

The total reaction:

$$
\mathrm{CuBi}_{2} \mathrm{O}_{4}+14 \mathrm{Li}^{+}+14 \mathrm{e}^{-} \rightleftharpoons \mathrm{Cu}+2 \mathrm{Li}_{3} \mathrm{Bi}+4 \mathrm{Li}_{2} \mathrm{O}
$$

Fig. $3 \mathrm{~b}$ depicts the first two charge and discharge voltage profiles of the hierarchical $\mathrm{CuBi}_{2} \mathrm{O}_{4}$ microspheres at a constant current density of $100 \mathrm{~mA} \mathrm{~g}^{-1}$. The initial discharge and charge capacities are 1344.4 and $969.2 \mathrm{~mA} \mathrm{~h} \mathrm{~g}^{-1}$ respectively, with a coulombic efficiency of $72.2 \%$. The relatively low coulombic efficiency can be ascribed to the decomposition of electrolyte and formation of a solid electrolyte interface (SEI) on the electrode surface. ${ }^{37,38}$ Clearly, several approximate voltage plateaus in the first discharge curve are related to the multi-step lithiation process shown in the first CV curves. Typically, the voltage plateaus at 1.40 and $0.70 \mathrm{~V}$ are corresponded to the reaction (1) and (2), respectively.

We found that there is strong temperature-dependence in electrochemical performance of hierarchical $\mathrm{CuBi}_{2} \mathrm{O}_{4}$ microspheres and higher temperature evidently increases the capacity and cycling performance. As shown in Fig. 3c, the long-term cycling performance of hierarchical $\mathrm{CuBi}_{2} \mathrm{O}_{4}$ microspheres is evaluated at $30{ }^{\circ} \mathrm{C}, 50{ }^{\circ} \mathrm{C}$ and $70{ }^{\circ} \mathrm{C}$, respectively. Clearly, the capacities at $70{ }^{\circ} \mathrm{C}$ are much larger than those capacities at $30{ }^{\circ} \mathrm{C}$ or $50{ }^{\circ} \mathrm{C}$ in all the cycles. This could be ascribed to the decreasing battery resistance and increase of the ion mobility of the electrolyte at elevated temperature. Besides, the capacity shows an interesting change during the cycling process at all the temperatures. At $70{ }^{\circ} \mathrm{C}$, the discharge capacity drops to $330.6 \mathrm{~mA} \mathrm{~h} \mathrm{~g}^{-1}$ during the first 20 cycles. Afterwards, the capacity starts to increase and maintains a constant value of about $525.0 \mathrm{~mA} \mathrm{~h} \mathrm{~g}{ }^{-1}$ after 100 cycles. Furthermore, the coulombic efficiency exceeds $98 \%$ throughout the cycling process, and it approaches to $99 \%$ over 500 cycles. Comparably, the discharge capacities of hierarchical $\mathrm{CuBi}_{2} \mathrm{O}_{4}$ microsphere drop to $180 \mathrm{~mA} \mathrm{~h} \mathrm{~g}^{-1}$ and $140 \mathrm{~mA} \mathrm{~h} \mathrm{~g}^{-1}$ during the first dozens of cycles, respectively, at $50{ }^{\circ} \mathrm{C}$ and $30{ }^{\circ} \mathrm{C}$. After 500 cycles, the discharge capacities recover to 415.3 and $293.7 \mathrm{~mA} \mathrm{~h} \mathrm{~g}^{-1}$ at
$50{ }^{\circ} \mathrm{C}$ and $30{ }^{\circ} \mathrm{C}$, respectively. The typical capacity comparisons at different temperatures are presented in Fig. S4. $\dagger$ As a result, the hierarchical $\mathrm{CuBi}_{2} \mathrm{O}_{4}$ microsphere shows higher capacity and better cycling stability in higher temperature environment. We have attempted to investigate the lithium storage ability of $\mathrm{CuBi}_{2} \mathrm{O}_{4}$ with different morphologies. Fig. $3 \mathrm{~d}$ shows the cycling performance of irregular $\mathrm{CuBi}_{2} \mathrm{O}_{4}$ microparticles at $70{ }^{\circ} \mathrm{C}$. The capacity of irregular $\mathrm{CuBi}_{2} \mathrm{O}_{4}$ microparticles approaches to zero after 100 cycles, demonstrating a very poor cycling performance. The capacity comparison is presented in Fig. S5. $\dagger$ The results indicate the hierarchical microsphere structure plays a vital role in lithium storage of the hierarchical $\mathrm{CuBi}_{2} \mathrm{O}_{4}$ microspheres.

The temperature-dependent property for lithium storage of the hierarchical $\mathrm{CuBi}_{2} \mathrm{O}_{4}$ microspheres could be ascribed to their unique hierarchical structure and outstanding thermostability. The schemes of the temperature-dependent mechanisms are shown in Fig. 4a-c. The Li-ions mobility mainly depends on electrolyte diffusion that is largely determined by the environment temperature. The higher temperature, the electrolyte diffusion is faster. As such, the Li-ions show faster migration rate at higher temperature, which can rapidly migrate into the inner of hierarchical $\mathrm{CuBi}_{2} \mathrm{O}_{4}$ microspheres. Furthermore, the hierarchical $\mathrm{CuBi}_{2} \mathrm{O}_{4}$ microspheres features outstanding thermostability and the hierarchical structure can be maintained at higher temperature. Therefore, the hierarchical $\mathrm{CuBi}_{2} \mathrm{O}_{4}$ microspheres exhibit higher capacity and better cycling performance at higher temperature. Nevertheless, the electrolyte diffusion into the inner of hierarchical $\mathrm{CuBi}_{2} \mathrm{O}_{4}$ microspheres is slow in the early cycles due to the diffusion resistance between electrode material surface and electrolyte. As a result, the capacity of hierarchical $\mathrm{CuBi}_{2} \mathrm{O}_{4}$ microsphere shows a fading process during the first dozens of cycles due to the lithiation reaction was limited on the surface of hierarchical $\mathrm{CuBi}_{2} \mathrm{O}_{4}$ microspheres. When the

\section{(a)}

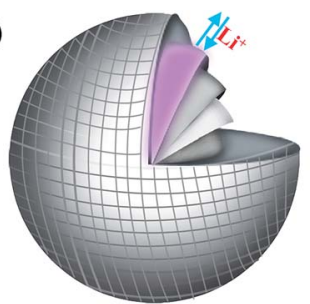

$30{ }^{\circ} \mathrm{C}$, Slow diffusion of Li-ions

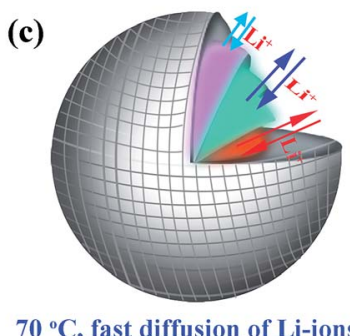

$70^{\circ} \mathrm{C}$, fast diffusion of Li-ions (c) (b)

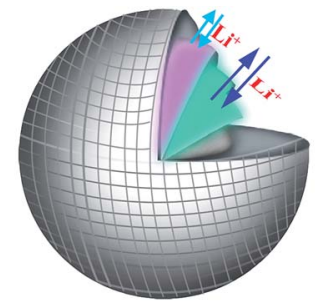

$50{ }^{\circ} \mathrm{C}$, Moderate diffusion of Li-ions (d)

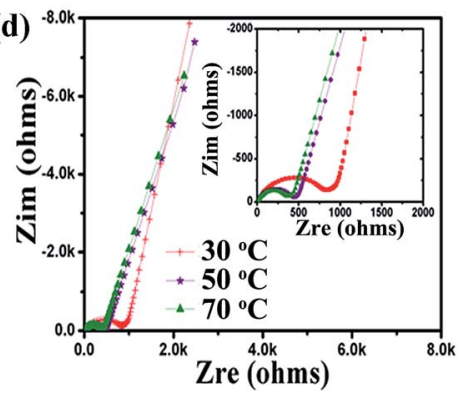

Fig. 4 (a)-(c) The schemes of temperature-dependent mechanisms of hierarchical $\mathrm{CuBi}_{2} \mathrm{O}_{4}$ microsphere; (d) Nyquist plots of the impedance at the 100th cycle (charging to $3.0 \mathrm{~V}$ ). 
electrolyte permeates into the inner of hierarchical $\mathrm{CuBi}_{2} \mathrm{O}_{4}$ microspheres, the lithiation reaction would be sufficient and thus the capacity of hierarchical $\mathrm{CuBi}_{2} \mathrm{O}_{4}$ microsphere turns to increase and keeps stable in the subsequent cycles. The higher temperature, the diffusion resistance is lower. Therefore, the hierarchical $\mathrm{CuBi}_{2} \mathrm{O}_{4}$ microspheres demonstrate a short capacity fading process at higher temperature. The electrochemical impendence spectroscopy (EIS) is performed to investigate the electrode process kinetics. The Nyquist plots in Fig. 4d show EIS curves after 100 cycles at different temperatures. All the impedance plots are made up of a depressed semicircle at high frequency, and a slope line at low frequency. The semicircle corresponds to the internal resistance $\left(R_{\mathrm{ct}}\right)$ and interfacial impedance $\left(R_{\mathrm{f}}\right)$ between the electrode and electrolyte. The slope line at low frequency indicates the Li-ions diffusion into the electrode material $\left(W_{\mathrm{o}}\right)$. The equivalent circuit model for hierarchical $\mathrm{CuBi}_{2} \mathrm{O}_{4}$ microsphere is shown in Fig. S6. $\dagger$ The values of $R_{\text {ct }}$ are 785.2 $\Omega, 369.2 \Omega$ and $245.1 \Omega$ for hierarchical $\mathrm{CuBi}_{2} \mathrm{O}_{4}$ microsphere anodes at $30{ }^{\circ} \mathrm{C}, 50{ }^{\circ} \mathrm{C}$ and $70{ }^{\circ} \mathrm{C}$, respectively. This confirms the lower internal resistance at higher temperature. The more data of EIS are presented in Table S2. $\dagger$ These significant results clearly demonstrate that the Li-ions mobility and electronic transfer rate are affected by environmental temperature.

The rate performance of hierarchical $\mathrm{CuBi}_{2} \mathrm{O}_{4}$ microspheres at different temperatures is shown in Fig. 5a. In consideration of the fact that the capacity keeps stable after 100 cycles, the rate capability measurements were performed after 100 cycles at a current rate of $100 \mathrm{~mA} \mathrm{~g}^{-1}$. When the temperature is $70{ }^{\circ} \mathrm{C}$, the $\mathrm{CuBi}_{2} \mathrm{O}_{4}$ microspheres display a reversible capacity of 538,499 , $459,403,361,312$ and $261 \mathrm{~mA} \mathrm{~h} \mathrm{~g}^{-1}$ at 100, 200, 400, 800, 1600, 3200 and $6400 \mathrm{~mA} \mathrm{~g}^{-1}$ respectively. Although the capacity is only $261 \mathrm{~mA} \mathrm{~h} \mathrm{~g}^{-1}$ at $6.4 \mathrm{~A} \mathrm{~g}^{-1}$, it recovers to $585 \mathrm{~mA} \mathrm{~h} \mathrm{~g}^{-1}$ after the current density returns to $100 \mathrm{~mA} \mathrm{~g}^{-1}$. This recovered capacity is even higher than the aforementioned value (538 $\mathrm{mA} \mathrm{h}^{-1}$ ) and reaches to $88.6 \%$ of the theoretical capacity
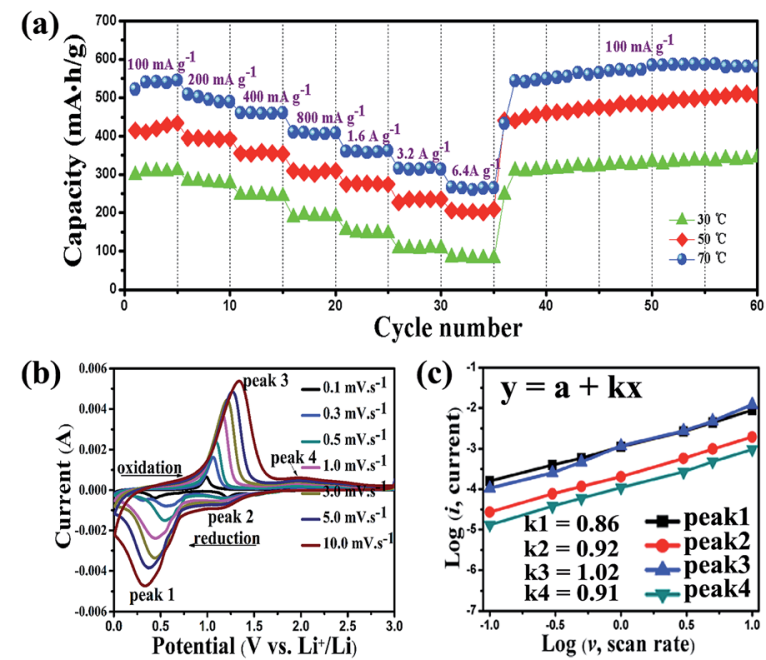

Fig. 5 (a) Rate capability at various current rates between $100 \mathrm{~mA} \mathrm{~g}^{-1}$ and $6.4 \mathrm{~A} \mathrm{~g}^{-1}$ were tested at 30,50 and $70{ }^{\circ} \mathrm{C}$. (b) CV curves at different scan rates after 100 cycles, and (c) $\log (i)$ versus $\log (\nu)$ plots at different redox states of the hierarchical $\mathrm{CuBi}_{2} \mathrm{O}_{4}$ microsphere.
(668 $\mathrm{mA} \mathrm{h} \mathrm{g}^{-1}$ ). For comparison, the hierarchical $\mathrm{CuBi}_{2} \mathrm{O}_{4}$ microspheres deliver capacities of 495 and $337 \mathrm{~mA} \mathrm{~h} \mathrm{~g}{ }^{-1}$, respectively, at $50{ }^{\circ} \mathrm{C}$ and $30^{\circ} \mathrm{C}$ after the current density returns to $100 \mathrm{~mA} \mathrm{~g}^{-1}$. Obviously, the hierarchical $\mathrm{CuBi}_{2} \mathrm{O}_{4}$ microspheres show a strong tolerance and favourable rate performance at higher temperature.

To explicate the good rate performance, CV curves of the hierarchical $\mathrm{CuBi}_{2} \mathrm{O}_{4}$ microspheres at different scan rates from 0.1 to $10 \mathrm{mV} \mathrm{s}^{-1}$ after 100 cycles are shown in Fig. $5 \mathrm{~b}$. When the scan rate is $0.1 \mathrm{mV} \mathrm{s}^{-1}$, two obvious reduction peaks at 1.25 and $0.44 \mathrm{~V}$ and two oxidation peaks at 1.99 and $0.97 \mathrm{~V}$ are observed, which recur in the subsequent scans. With increasing the scan rate, the peak current increases without being proportional to the square root of the scan rate, indicating that the electrochemical reactions are composed of non-faradaic and faradaic processes. $^{38-40}$ The relationship between peak current $(i)$ and scan rate $(\nu)$ could be illustrated as follows:

$$
\begin{gathered}
i=a \nu^{\mathrm{b}} \\
\log (i)=b \log (\nu)+\log (a)
\end{gathered}
$$

where $a$ and $b$ are adjustable parameters. The $b$ value determines the reaction type of Li-ions insertion/extraction. When the value of $b$ is 0.5 , the electrochemical reaction is dominated by ionic diffusion (faradaic). When the value of $b$ is 1 , the process is mainly decided by pseudo-capacitive (non-faradaic) process. Fig. 5c depicts the linear relationship between $\log (i)$ and $\log (\nu)$ at every peak potential. The $b$ values of the four peaks are $1.10,0.83,0.94$, and 0.98 , meaning that the electrochemical reactions of the $\mathrm{CuBi}_{2} \mathrm{O}_{4}$ microspheres are mainly controlled by the pseudo-capacitive process that leads to fast Li-ion insertion/ extraction (high rate capability).

To verify the lithium storage mechanism of hierarchical $\mathrm{CuBi}_{2} \mathrm{O}_{4}$ microspheres, ex situ XRD, XPS spectra and HR-TEM were performed after 100 cycles. Fig. 6a shows the XRD patterns of the $\mathrm{CuBi}_{2} \mathrm{O}_{4}$ microsphere at different charge/
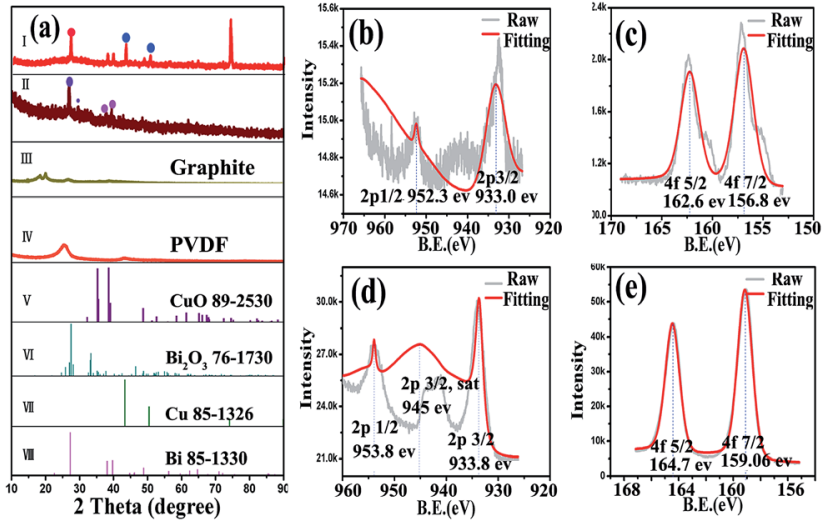

Fig. 6 Structural evolutions of hierarchical $\mathrm{CuBi}_{2} \mathrm{O}_{4}$ microsphere during the electrochemical reaction with lithium are analyzed by ex situ after dismantling the cells. (a) XRD profiles of hierarchical $\mathrm{CuBi}_{2} \mathrm{O}_{4}$ microsphere electrodes with discharging to $0.01 \mathrm{~V}(\mathrm{I})$ and charging to $3.0 \mathrm{~V}$ (II) at the 50th cycle. (b)-(e) XPS spectra of the elements Bi and $\mathrm{Cu}$ at the 50th cycle. 
discharge status. During the discharge process (discharging to $0.01 \mathrm{~V}$ ), the characteristic peaks of $\mathrm{CuBi}_{2} \mathrm{O}_{4}$ disappear and the observed peaks at around $27^{\circ}$ and $43^{\circ}$ (Fig. 6a(I, VII and VIII)) could be assigned to monoclinic Bi phase (JCPDS Card no. 851330) and cubic $\mathrm{Cu}$ phase (JCPDS Card no. 85-1326), respectively. The phases of $\mathrm{LiBi}$ or $\mathrm{Li}_{3} \mathrm{Bi}$ are scarcely detected due to their instability in air.

The XPS spectra (Fig. 6b and c) can be fitted better and the peaks match well with the standard binding energy of pure copper and bismuth, indicating the bismuth and cuprum exist as elementary substance. The HR-TEM (Fig. S7a and b†) show clear lattice fringes and the measured lattice spacings of about $0.324,0.196$ and $0.180 \mathrm{~nm}$ correspond well to the (012) plane of $\mathrm{Bi}$ and the (111) and (200) planes of $\mathrm{Cu}$. This confirms the phase change from tetragonal $\mathrm{CuBi}_{2} \mathrm{O}_{4}$ to monoclinic $\mathrm{Bi}$ and cubic $\mathrm{Cu}$, consistent well with the ex situ XRD study. During the charge process, the obtained species after being charged to $3.0 \mathrm{~V}$ are clarified. The XRD peaks shown in Fig. $6 \mathrm{a}$ (II) could be indexed well to the $\mathrm{Bi}_{2} \mathrm{O}_{3}$ (JCPDS no. 76-1730) and $\mathrm{CuO}$ (JCPDS no. 892530). The XPS spectra (Fig. 6d and e) and HR-TEM (Fig. S7c and $\mathrm{d} \dagger$ ) all confirm the presence of $\mathrm{Bi}_{2} \mathrm{O}_{3}$ and $\mathrm{CuO}$. The 2p3/2 satellite peak (Fig. 6e) of $\mathrm{Cu}$ is a key role to verify the $\mathrm{Cu}$ (II) exists. The lattice fringes with $d$-spacings of 0.3147 and $0.324 \mathrm{~nm}$ (Fig. S7c $\dagger$ ) are indexed to the (012) and (121) plane of $\mathrm{Bi}_{2} \mathrm{O}_{3}$ and the measured lattice spacings of 0.231 and $0.234 \mathrm{~nm}$ (Fig. S7d $\dagger$ ) correspond well to the (200) and (111) plane of $\mathrm{CuO}$, respectively. All the results accord well with the lithium storage mechanism of hierarchical $\mathrm{CuBi}_{2} \mathrm{O}_{4}$ microspheres deduced by CV investigations.

\section{Conclusions}

In summary, hierarchical $\mathrm{CuBi}_{2} \mathrm{O}_{4}$ microspheres assembled by primary tetragonal nanoparticles have been prepared via a facile and eco-friendly hydrothermal method. The as-synthesized hierarchical $\mathrm{CuBi}_{2} \mathrm{O}_{4}$ microspheres are first used as anode materials for LIBs, exhibiting strong temperature-dependent properties that higher temperature evidently enhances the electrochemical performance. At an elevated temperature of $70{ }^{\circ} \mathrm{C}$, the hierarchical $\mathrm{CuBi}_{2} \mathrm{O}_{4}$ microspheres can deliver a stable discharge capacity of $525.1 \mathrm{~mA} \mathrm{~h}^{-1}$ after 500 cycles at a current rate of $100 \mathrm{~mA} \mathrm{~g}^{-1}$. After being cycled at a high current density $\left(6.4 \mathrm{~A} \mathrm{~g}^{-1}\right)$, they can still retain a capacity of $585 \mathrm{~mA} \mathrm{~h}$ $\mathrm{g}^{-1}$ when the current density recovers to $100 \mathrm{~mA} \mathrm{~g}^{-1}$. The superior high-temperature electrochemical performance of the hierarchical $\mathrm{CuBi}_{2} \mathrm{O}_{4}$ microspheres could be ascribed to their unique hierarchical structure and outstanding thermostability. The lithium storage mechanism of the hierarchical $\mathrm{CuBi}_{2} \mathrm{O}_{4}$ microspheres has proven to be a multi-step lithiation process. The superior high-temperature electrochemical performance of the hierarchical $\mathrm{CuBi}_{2} \mathrm{O}_{4}$ microspheres endows them with promising applications in a wide temperature range.

\section{Acknowledgements}

This work was supported by the National Basic Research Program of China (Grant No. 2015CB755602, 2014CB643506,
2013CB922104), NSFC (21474034, 51673037). We also thank the Analytical and Testing Center of Huazhong University of Science and Technology and the Center of Micro-Fabrication and Characterization (CMFC) of WNLO for use of their facilities.

\section{Notes and references}

1 Z. B. Yang, J. Ren, Z. T. Zhang, X. L. Chen, G. Z. Guan, L. B. Qiu, Y. Zhang and H. S. Peng, Chem. Rev., 2015, 115, 5159.

2 M. Srivastava, J. Singh, T. Kuila, R. K. Layek, N. H. Kime and J. H. Lee, Nanoscale, 2015, 7, 4820.

3 M. S. Whittingham, Chem. Rev., 2014, 114, 11414.

4 X. F. Wang, Y. Chen, O. G. Schmidtbc and C. L. Yan, Chem. Soc. Rev., 2016, 45, 1308.

5 X. D. Xiang, K. Zhang and J. Chen, Adv. Mater., 2015, 27, 5343.

6 C. Fang, Y. H. Huang, W. X. Zhang, J. T. Han, Z. Deng, Y. L. Cao and H. X. Yang, Adv. Energy Mater., 2016, 6, 1501727.

7 L. Mai, X. Tian, X. Xu, L. Chang and L. Xu, Chem. Rev., 2014, 114, 11828.

8 D. Higgins, P. Zamani, A. Yu and Z. W. Chen, Energy Environ. Sci., 2016, 9, 357.

9 B. J. Hassoun, G. Derrien, S. Panero and B. Scrosati, $A d v$. Mater., 2008, 20, 3169.

10 P. G. Balakrishnan, R. Ramesh and T. P. Kumar, J. Power Sources, 2006, 15, 5401.

11 L. Mohana Reddy, A. Srivastava, S. R. Gowda, H. Gullapalli, M. Dubey and P. M. Ajayan, ACS Nano, 2010, 4, 6337.

12 B. Stiaszny, J. C. Ziegler, E. E. Krauß, M. Zhang, J. P. Schmidt and E. I. Tiffée, J. Power Sources, 2014, 258, 61.

13 J. Y. Ji, H. X. Ji, L. L. Zhang, X. Zhao, X. Bai, X. F. Fan, F. B. Zhang and R. S. Ruoff, Adv. Mater., 2013, 25, 4673.

14 Y. F. Ma, H. C. Chang, M. Zhang and Y. S. Chen, Adv. Mater., 2015, 27, 5296.

15 P. Roy and S. K. Srivastava, J. Mater. Chem. A, 2015, 3, 2454.

16 R. B. Wu, X. K. Qian, K. Zhou, J. Wei, J. Lou and P. M. Ajayan, ACS Nano, 2014, 8, 6297.

17 A. Banerjee, U. Singh, V. Aravindan, M. Srinivasan and S. Ogalea, Nano Energy, 2013, 2, 1158.

18 R. B. Wu, X. K. Qian, F. Yu, H. Liu, K. Zhou, J. Wei and Y. Z. Huang, J. Mater. Chem. A, 2011, 1, 11126.

19 S. Yang, W. B. Yue, J. Zhu, Y. Ren and X. J. Yang, Adv. Funct. Mater., 2013, 23, 3570.

20 Y. M. Sun, X. H. Hu, W. Luo, F. F. Xia and Y. H. Huang, Adv. Funct. Mater., 2013, 23, 2436.

21 K. Z. Cao, L. F. Jiao, Y. C. Liu, H. Q. Liu, Y. J. Wang and H. T. Yuan, Adv. Funct. Mater., 2015, 25, 1082.

22 J. Lin, Z. W. Peng, C. S. Xiang, G. D. Ruan, Z. Yan, D. Natelson and J. M. Tour, ACS Nano, 2013, 7, 6001.

23 C. He, S. Wu, N. Q. Zhao, C. S. Shi, E. Z. Liu and J. J. Li, ACS Nano, 2013, 7, 4459.

24 Y. L. Li, M. A. Trujillo, E. Fu, B. Patterson, L. Fei, Y. Xu, S. Deng, S. Smirnove and H. M. Luo, J. Mater. Chem. A, 2013, 1, 12123. 
25 A. Elaziouti, N. Laouedj, A. Bekka and R. Vannier, J. King Saud Univ., Sci., 2015, 27, 120.

26 A. A. Aref, A. A. Muneerah, D. M. Sun, H. Wang, C. Qing and Y. W. Tang, Mater. Sci. Semicond. Process., 2015, 29, 262.

27 S. Yuvaraj, K. Karthikeyan, D. Kalpana, Y. S. Lee and R. K. Selvan, J. Colloid Interface Sci., 2016, 469, 47.

28 Y. Y. Deng, Y. J. Chen, B. Chen and J. H. Ma, J. Alloys Compd., 2013, 559, 116.

29 Y. Nakabayashi, M. Nishikawa and Y. Nosaka, Electrochim. Acta, 2014, 125, 191.

30 X. M. Wang, T. Nishina and I. Uchida, J. Power Sources, 2002, 104, 96.

31 A. A. Ensafi, N. Ahmadi and B. Rezaei, J. Alloys Compd., 2015, 652, 39.

32 S. Yuan, X. L. Huang, D. L. Ma, H. G. Wang and F. Z. Meng, Adv. Mater., 2014, 26, 2273.
33 F. Parmigiani, G. Pacchioni, F. Illas and P. S. Bagus, J. Electron Spectrosc. Relat. Phenom., 1992, 59, 255-269.

34 X. Guo, Y. Q. Sun and K. Cui, Sens. Actuators, B, 1996, 31, 139. 35 W. D. Oh, S. K. Lua, H. Dong and T. T. Lim, Nanoscale, 2013, 1.

36 C. M. Parka, S. Yoon, S. Lee and H. J. Sohna, J. Power Sources, 2009, 186, 206-210.

37 F. H. Yang, F. Yu, Z. Zhang, K. Zhang, Y. Q. Lai and J. Li, Chem.-Eur. J., 2016, 22, 2333.

38 K. Zhang, Z. Hu, X. Liu, Z. L. Tao and J. Chen, Adv. Mater., 2015, 27, 3305.

39 Z. Hu, Z. Q. Zhu, F. Y. Cheng, K. Zhang, J. B Wang, C. C. Chen and J. Chen, Energy Environ. Sci., 2015, 8, 1309.

40 M. Trybula, P. Fima and W. Gasior, Thermochim. Acta, 2014, 588, 16-21. 